\title{
Matily Herbal Drink May Reduce Oxidative Stress, Hyperglycemia, and Hyperlipidemia and Increases Immunity- Case Study Reports
}

By John T. Eapen

Introduction- Oxygen is an element indispensable for all aerobic organisms to sustain life (1). Cells produce energy mainly in the mitochondria through oxidative phosphorylation, a series of electron transfer in the Electron Transport Chain (ETC), where oxygen is the final electron acceptor. During this process, it creates free radicles by the mitochondria. Oxidative stress produces free radicals. A $70 \mathrm{Kgs}$ man may produce nearly $2 \mathrm{Kg}$ of free radicals in his body in a year (2). It is comparatively a huge amount. Examples offree radicals with one or more unpaired electrons are superoxide, hydroxyl, andnitric oxide radicals $(1,3)$.

A molecule like oxygen is stable when it shares its electrons in the paired state, when it loses or gains an extra electron, it becomes unstable. This condition leads them to "steal" or take it from other biomolecules. This process leaves the biomolecules in the oxidative state, which can start pathological conditions. For example, when Low-Density Lipoproteins when becomingoxidized, causes atherosclerosis in the blood vessels and cause plaques inside the arteries (4).

GJMR-F Classification: NLMC Code: QW 540

Strictly as per the compliance and regulations of:

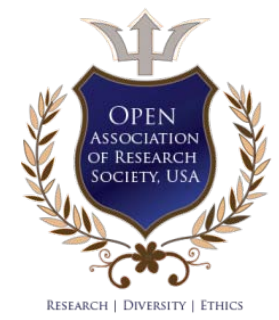

(C) 2020. John T. Eapen. This is a research/review paper, distributed under the terms of the Creative Commons AttributionNoncommercial 3.0 Unported License http://creativecommons.org/licenses/by-nc/3.0/), permitting all non-commercial use, distribution, and reproduction in any medium, provided the original work is properly cited. 


\title{
Matily Herbal Drink May Reduce Oxidative Stress, Hyperglycemia, and Hyperlipidemia and Increases Immunity- Case Study Reports
}

\author{
John T. Eapen
}

\section{INTRODUCTION}

$\longrightarrow x$ xygen is an element indispensable for all aerobic organisms to sustain life (1). Cells produce energy mainly in the mitochondria through oxidative phosphorylation, a series of electron transfer in the Electron Transport Chain (ETC), where oxygen is the final electron acceptor. During this process, it creates free radicles by the mitochondria. Oxidative stress produces free radicals. A $70 \mathrm{Kgs}$ man may produce nearly $2 \mathrm{Kg}$ of free radicals in his body in a year (2). It is comparatively a huge amount. Examples offree radicals with one or more unpaired electrons are superoxide, hydroxyl, andnitric oxide radicals $(1,3)$.

A molecule like oxygen is stable when it shares its electrons in the paired state, when it loses or gains an extra electron, it becomes unstable. This condition leads them to "steal" or take it from other biomolecules. This process leaves the biomolecules in the oxidative state, which can start pathological conditions. For example, when Low-Density Lipoproteins when becomingoxidized, causes atherosclerosis in the blood vessels and cause plaques inside the arteries (4).

Oxidative stress and disease remained a chicken and egg puzzle for a long time. Earlier it was believed that disease caused oxidative stress in the human body. Now the consensus among medical fraternity is that oxidative stress leads to various disease conditions.

"The human body has several mechanisms to counteract oxidative stress by producing antioxidants, which are either naturally produced in situ, or externally supplied through foods and/or supplements"(1). Antioxidants provide electrons needed for the stressed molecules and eliminate the free radicals (5).

There are many biochemical markers to measure the quantity of free radical status in the body. An excessive free radical produces fatigue in the human body, and we could take this as a general standard for the common man to assess the status of his body. Thus wellness of human health is inversely proportional to the free radicals in the body.

Author: MEEISATCODE, Dahanu Road, Palghar Dist. - 401 502. India. e-mail: jeteapen@gmail.com
In this communication, we want to report a herbal drink (Matily Drink) we designed with natural products and tested in patients as case studies and among some volunteers. The pharmacological means of controlling hyperglycemia and hyperlipidemia are expensive for the poor masses without and income and insurance. Hence we developed a drink with natural ingredients and tested as a case study and on some volunteers. It reduced weight, hypoglycemia, and hyperlipidemia and gave better wellness feeling, even relieving wheezing difficulty in the patient.

In another case study, with a person who was a chain smoker and had a frequent cough, found relief for his cough after taking the drink for a month.

All the volunteers reported wellness feeling and found that they were energetic after taking this drink.

Based on these encouraging results, we were about to commercialize the product. However, now in the corona pandemic season, we bring it to the public domain hoping this drink may help people to boost their immunity and also some clinicians will try it on COVID 19 patients to see whether the severity of lung infection is reduced, as we found some benefit to the lungs in the above case studies.

\section{il. Rational behind Designing and TEsting OF DRINK}

In December 2017, an elderly male patient of 62 years with a history of cardiac asthma presented his case to a cardiologist. The cardiologist wanted to rule out ischemic cardiac asthma and suggested to the patient to undergo an angiogram. He prescribed the following medicines for the patient. Glucophage for blood sugar, Starvas to lower cholesterol, Clopilet A for thinning of blood, Losar 50 for blood pressure, Selaken $\mathrm{XL}$ as beta-blocker, Imdur 30mg for angina, and Dytor $10 \mathrm{mg}$ to remove excess water from the body.

The patient was already on Loser 50 for his blood pressure and he continued the same from the prescription list. He did not take other medicines because he was not sure whether he could take the medications regularly because of his poor economic condition. He took Dytor whenever he felt bloated. Proper exercises reduced bloated feeling, and in those days, he avoided Dytor. 
The patient had diabetics for seven years. In the beginning, he took medication for one month, and he was feeling starving after taking the medicines. So he discontinued medication and started with diet and exercise to control the blood sugar levels. He used to take a small quantity meal four or five times a day. He used to walk at least two kilometers every day.

With the above prescription in his hand, the patient was searching for natural products that will help his condition. He developed a herbal drink with the following ingredients, and the reasons for selecting them are in the reference.

Okra has antidiabetic and anti-fatigue properties. It also reduces hyperlipidemia $(6,7)$. Mint leaves stimulate bile secretion, which uses cholesterol in the blood and may thus reduce cholesterol levels in the blood naturally (8). Curry leaves are good for liver as it has got anti hepatotoxicity effect $(9,10)$. Ginger has medicinal properties, and it has blood-thinning capability $(11,12)$. Lemon has various properties, and it is rich in Vitamin C $(13,14)$. Sometimes, we used lemon with its peels for making the drink. We mention elsewhere the health benefits of lemon peels (15). Sea salt with no anti-caking agent and sugar was added for taste (optional).

All ingredients and about $200 \mathrm{ml}$ water was added in a blender. It was ground and blended with water for a few minutes. It was made up to $750 \mathrm{ml}$, and filtered through a strainer. When the constituents were whipped well, there was no trace of mucilage of okra in the drink.

We give a concoction and procedure in note 1 .

\section{ili. Results and Discussion}

Table 1 shows different parameters before and after taking the drink.

Table 1: The weight, blood glucose, total cholesterol, HDL and LDL in the patient before and after taking Matily Drink

\begin{tabular}{|c|c|c|c|}
\hline $\begin{array}{c}\text { Parameters } \\
\text { measured }\end{array}$ & $\begin{array}{c}\text { Before taking } \\
\text { the drink }\end{array}$ & \multicolumn{2}{|c|}{ After taking the drink } \\
\hline $\begin{array}{c}12 / 12 / 2017 \\
\text { Blood glucose (mg/dl) } \\
\text { (random) }\end{array}$ & 271 & - & $19 / 06 / 2018$ \\
\hline $\begin{array}{c}\text { Blood glucose fasting } \\
\text { (mg/dl) }\end{array}$ & - & 123.5 & 134.7 \\
\hline $\begin{array}{c}\text { Blood glucose } \\
\text { postprandial (mg/dl) }\end{array}$ & - & 167.5 & 156.9 \\
\hline $\begin{array}{c}\text { Total cholesterol } \\
\text { (mg/dl) }\end{array}$ & 220 & 182.7 & - \\
\hline HDL (mg/dl) & 38.0 & 44.0 & - \\
\hline LDL (mg/dl) & 130 & 128.0 & - \\
\hline Body weight (Kgs) & 95 & 89 & 86 \\
\hline
\end{tabular}

Table 2: Lipid profile after taking Matily Drink for three months

\begin{tabular}{|c|c|c|c|}
\hline Test & Value & Units & Ref Range \\
\hline Appearance & Clear & Mg/dl & $140-240$ \\
\hline $\begin{array}{c}\text { S. Total } \\
\text { cholesterol }\end{array}$ & 182.7 & $\mathrm{Mg} / \mathrm{dl}$ & $30-65$ \\
\hline $\begin{array}{c}\text { S.HDL } \\
\text { Cholesterol }\end{array}$ & 44.0 & $\mathrm{Mg} / \mathrm{dl}$ & $25-160$ \\
\hline Triglycerides & 94.4 & $\mathrm{Mg} / \mathrm{dl}$ & $0-130$ \\
\hline $\begin{array}{c}\mathrm{LDL} \\
\text { cholesterol }\end{array}$ & 128.0 & $\mathrm{Mg} / \mathrm{dl}$ & $10-30$ \\
\hline $\begin{array}{c}\text { S.VLDL } \\
\text { Cholesterol }\end{array}$ & 28.0 & $\mathrm{Mg} / \mathrm{dl}$ & $3-5$ \\
\hline $\begin{array}{c}\text { TC/HDLC } \\
\text { ratio }\end{array}$ & 4.1 & $\mathrm{Mg} / \mathrm{dl}$ & $\mathrm{Up}$ to 3.5 \\
\hline $\begin{array}{c}\mathrm{LDLC} / \mathrm{HDLC} \\
\text { ratio }\end{array}$ & 2.9 & & \\
\hline
\end{tabular}

Results are shown in Tables 1 and 2 shows that Matily drink had some beneficial benefits to the patient.
The weight of the patient reduced from $95 \mathrm{kgs}$ to $86 \mathrm{kgs}$ in about six months with no crash dieting or 
excess exercises. It was a natural way of shedding weight. It remained in that state as long as the patient limited his calorie intake was same and continued his daily walk of two $\mathrm{km}$.

The total cholesterol of the patient was always between 220 to $240 \mathrm{mg} / \mathrm{dl}$ in the past. But within three months, it lowered the total cholesterol to $182 \mathrm{mg} / \mathrm{dl}$. Similarly, HDL cholesterol was always between 35 to 38 in the past. It rose to $44 \mathrm{mg} / \mathrm{dl}$ within three months' with Matily Drink. Total cholesterol / HDL Cholesterol ratio was 4.1, and the LDL cholesterol / HDL cholesterol was 2.9, which was within the acceptable range (Table 2).

Matily, Drink influenced the blood sugar of the patient. The patient always took a limited amount of free sugar in his tea. He never avoided free sugar. His random blood sugar was $271 \mathrm{mg} / \mathrm{dl}$ in the beginning before he started taking Matily Drink. In three months, the fasting sugar was $123.5 \mathrm{mg} / \mathrm{dl}$, and postprandial sugar was $167.5 \mathrm{mg} / \mathrm{dl}$.

The patient had some wheezing problems in the beginning before starting the course. However, it reduced with Matily Drink. Before taking the MatilyDrink patient had difficulty climbing steps, especially in the morning when the temperatures were down. However, maybe because of weight reduction, reduction of blockage of blood vessels and, or improved microbiome in the gut, patient stopped having difficulty in climbing steps.

The case study presented here shows that certain natural products can control hyperglycemia and hyperlipidemia without depending on pharmacological methods. Cholesterol is essential for the body, and our body produces it in the liver. The patient did not prefer the use of statins to manipulate the synthesis of cholesterol by the liver. Similarly, instead of depending on pharmacological methods to change the blood thinning process, he preferred natural products like ginger. The drink also improved his lung function, and it reduced wheezing problems.

In another case study, a 48-year-old male on chain-smoking of, "beedies", a crudely prepared cigar, took Matily drink to boost his immune system during COVID 19 lockdown. He always had frequent cough, and it disappeared after one month.

We mention the properties of the ingredients used in the drink and its benefits on human health in the references given.

To conclude: In the case-studies given above show the benefits of Matily drink, especially to those who cannot afford pharmacological methods. The wellness feelings reported by volunteers could show the reduction of free radicals in their bodies with the drink. It reduces free radical generation in the human body when hyperglycemia and hyperlipidemia are under control. The body will increase its immunity. Since Matily drink shows a beneficial effect on the functioning of lungs, it is worth checking whether it could reduce the severity of disease in the COVID 19 patients.

Note 1. Preparation of Matily Drink

Okra - one small one

Ginger - about $2 \mathrm{~cm}$ long

Mint - 2 or 3 leaves

Curry leaves - 2 or 3 leaves

Lemon - one

Sea salt - to taste

Sugar - to taste

All these were blended in a mixer with about $200 \mathrm{ml}$ water, and finally strained. The total volume was made to $750 \mathrm{ml}$ with water and the drink was consumed throughout the day.

Disclaimer: Any patients on pharmacological methods to control blood sugar, cholesterol, and blood thinning process should try this drink only under medical supervision.

\section{AcKnowledgments}

The author named the drink as Matily in remembrance of his father, Mr. M.E. Eapen (19262018), known among his American friends as "MAT" and who continuously encouraged the author to innovate methods to ease the suffering of the afflicted.

\section{References Références Referencias}

1. Pham-Huy, L. A., He, H., \& Pham-Huy, C. (2008). Free radicals, antioxidants in disease and health. International journal of biomedical science: IJBS, 4(2), 89-96.

2. Lewis C., A. (2018). Enteroimmunology: A guide to prevention and treatment of chronic inflammatory disease. Psy Press, Carrabelle Florida. Ed 3.06, Feb 2018.

3. Lobo, V., Patil, A., Phatak, A., \& Chandra, N. (2010). Free radicals, antioxidants and functional foods: Impact on human health. Pharmacognosy reviews, 4(8), 118-126. https://doi.org/10.4103/ 0973-7847.70902

4. Heinecke J.W. (2006). Lipoprotein oxidation in cardiovascular disese: chief culprit or innocent by stander? The Journal of experimental medicine, 203(4), 813-816. https://doi.org/10.1084/ jem.20060218

5. Norma Francenia Santos-Sánchez, Raúl SalasCoronado, Claudia Villanueva-Cañongo and Beatriz Hernández-Carlos (March 22nd 2019). Antioxidant Compounds and Their Antioxidant Mechanism, Antioxidants, Emad Shalaby, IntechOpen, DOI: 10.5772/intechopen.85270. Available from: https:// www.intechopen.com/books/antioxidants/antioxidan t-compounds-and-their-antioxidant-mechanism

6. Xia, F., Zhong, Y., Li, M., Chang, Q., Liao, Y., Liu, X., \& Pan, R. (2015). Antioxidant and Anti-Fatigue 
Constituents of Okra. Nutrients, 7(10), 8846-8858. https://doi.org/10.3390/nu7105435.

7. Durazzo, A., Lucarini, M., Novellino, E., Souto, E. B., Daliu, P., \& Santini, A. (2018). Abelmoschusesculentus (L.): Bioactive Components' Beneficial Properties-Focused on Antidiabetic Role-For Sustainable Health Applications. Molecules (Basel, Switzerland), 24(1), 38. https://doi.org/10.3390/molecules24010038.

8. Zong, L., Qu, Y., Luo, D. X., Zhu, Z. Y., Zhang, S. Su, Z., Shan, J. C., Gao, X. P., \& Lu, L. G. (2011). Preliminary experimental research on the mechanism of liver bile secretion stimulated by peppermint oil. Journal of digestive diseases, 12(4), 295-301. https://doi.org/10.1111/j.1751-2980. 2011. 00513.x

9. Firdaus, S. B., Ghosh, D., Chattyopadhyay, A., Dutta, M., Paul, S., Jana, J., Basu, A., Bose, G., Lahiri, H., Banerjee, B., Pattari, S., Chatterjee, S., Jana, K., \& Bandyopadhyay, D. (2014). Protective effect of antioxidant rich aqueous curry leaf (Murrayakoenigii) extract against gastro-toxic effects of piroxicam in male Wistar rats. Toxicology reports, 1, 987-1003. https://doi.org/10.1016/j. toxrep.2014.06.007

10. Ghasemzadeh, A., Jaafar, H. Z., Rahmat, A., \&Devarajan, T. (2014). Evaluation of Bioactive Compounds, Pharmaceutical Quality, and Anticancer Activity of Curry Leaf (Murrayakoenigii L.). Evidence-based complementary and alternative medicine: eCAM, 2014, 873803. https://doi.org/ 10.1155/2014/873803

11. MohdSahardi, N., \&Makpol, S. (2019). Ginger (Zingiberofficinale Roscoe) in the Prevention of Ageing and Degenerative Diseases: Review of Current Evidence. Evidence-based complementary and alternative medicine: eCAM, 2019, 5054395. https://doi.org/10.1155/2019/5054395

12. Verma, S. K., Singh, J., Khamesra, R., \& Bordia, A. (1993). Effect of ginger on platelet aggregation in man. The Indian journal of medical research, 98, 240-242.

13. Lv, X., Zhao, S., Ning, Z., Zeng, H., Shu, Y., Tao, O., Xiao, C., Lu, C., \& Liu, Y. (2015). Citrus fruits as a treasure trove of active natural metabolites that potentially provide benefits for human health. Chemistry Central journal, 9, 68. https:// doi.org/10.1186/s13065-015-0145-9

14. Kim, M. J., Hwang, J. H., Ko, H. J., Na, H. B., \& Kim, J. H. (2015). Lemon detox diet reduced body fat, insulin resistance, and serum hs-CRP level without hematological changes in overweight Korean women. Nutrition research (New York, N.Y.), 35(5), 409-420. https://doi.org/10.1016/j.nutres.2015. 04.001

15. Lv, X., Zhao, S., Ning, Z., Zeng, H., Shu, Y., Tao, O., Xiao, C., Lu, C., \& Liu, Y. (2015). Citrus fruits as a treasure trove of active natural metabolites that potentially provide benefits for human health. Chemistry Central journal, 9, 68. https:// doi.org/10.1186/s13065-015-0145-9. 